\title{
Predictive Models for Optimisation of Acetone Mediated Extraction of Polyphenolic Compounds from By-Product of Cider Production
}

\author{
Salis Ibrahim ${ }^{*}$, Regina Santos ${ }^{2}$, Steve Bowra ${ }^{3}$ \\ ${ }^{1}$ University for Development Studies, Tamale, Ghana \\ ${ }^{2}$ University of Birmingham, Edgbaston, Birmingham, UK \\ ${ }^{3}$ Department of Research and Development, Phytatec (UK) Ltd., Plas Gogerddan, Aberystwyth, UK \\ Email: ‘isalis@uds.edu.gh
}

How to cite this paper: Ibrahim, S., Santos, R. and Bowra, S. (2020) Predictive Models for Optimisation of Acetone Mediated Extraction of Polyphenolic Compounds from By-Product of Cider Production. Advances in Chemical Engineering and Science, 10, 81-98. https://doi.org/10.4236/aces.2020.102006

Received: February 9, 2020

Accepted: March 24, 2020

Published: March 27, 2020

Copyright $\odot 2020$ by author(s) and Scientific Research Publishing Inc. This work is licensed under the Creative Commons Attribution International License (CC BY 4.0).

http://creativecommons.org/licenses/by/4.0/

\begin{abstract}
Response surface methodology (RSM) was applied to provide predictive models for optimisation of extraction of selected polyphenolic compounds from cider apple pomace under aqueous acetone. The design of experiment (DoE) was conducted to evaluate the influence of acetone concentration $\%(\mathrm{v} / \mathrm{v})$, solid-to solvent ratio $\%(\mathrm{w} / \mathrm{v})$, temperature $\left({ }^{\circ} \mathrm{C}\right)$ and extraction time $(\mathrm{min})$ and their interaction on phenolic contents, using the Central Composite Rotatable Design (CCRD). The experimental data were analysed to fit statistical models for recovery of phenolic compounds. The selected models were significant $(\mathrm{P}<0.05)$ and insignificant lack of fits $(\mathrm{P}>0.05)$, except for Chlorogenic acid and Quercetin 3 -glucoside which had significant lack of fits $(\mathrm{P}<0.05)$. All models had satisfactory level of adequacies with coefficients of regression $R^{2}>0.9000$ and adjusted $R_{A d j}^{2}$ reasonable agrees with predicted $R_{P r i}^{2}$. Coefficient of variation $<5 \%$ for each determination at the $95 \%$ confidence interval. These models could be relied upon to achieve optimal concentrations of polyphenolic compounds for applications in nutraceutical, pharmaceutical and cosmetic industries.
\end{abstract}

\section{Keywords}

Cider Apple Pomace, Predictive Models, Optimisation, Polyphenolic Compounds

\section{Introduction}

Mathematical modelling is an indispensable tool in many applications in science 
and engineering. It is the art of translating problems from an application area into tractable mathematical formulations whose theoretical and numerical analysis provides deep understanding to answers and guidance that are useful for originating applications [1]. Mathematical concepts and language are employed to facilitate proper explanation of the system and also explain the effects of different factors, and to make predictions of their behaviour [2]. Modelling based on mathematics provides thorough understanding of the system to be modelled and allows different applications of modern computing capabilities [3]. Models serve as tools for the understanding of very important and complex processes or systems [4]. Different types of models have been proposed and applied in chemical process for optimisation and for designing experiments to give better understanding of complex systems. Response surface methodology (RSM) is a multivariate statistical technique that evaluates the interrelationship between process parameters and responses [5] [6] [7]. Response Surface Methodology was set out by Box et al., 1950 [8] and was a collection of mathematical and statistical techniques used to improve the performance of systems for maximum benefits [9]. By fitting a polynomial equation to an observed data from within a designed of experiment (DoE), the technique was able to predict the behaviour of a response based on the set of independent variables [9]. Response surface methodology provides adequate information from a relatively fewer experimental runs compared to one factor at time procedure which involved plenty of time in experimental trials for model generation. The one factor at a time procedure requires more experiments to be able to explain the interaction of the independent variables on overall dependent quantity or response. Response surface methodology utilises three (3) levels of independent factors to produce experimental designs and employ polynomial models for analysis. RSM has important application in process development, formulation and design of contemporary products in addition to established ones. The technique is widely applicable in chemical and biochemical processes for varied objectives [10]. Comprehensive description of design of experiments by response surface methodology can be obtained from [11] [12] [13].

The current research seeks to demonstrate the possibility of developing predictive models that are reliable for optimisation of the recovery of polyphenolic compounds from cider apple pomace using aqueous acetone as a solvent. Apple pomace is the residue of apple juice and cider production and composed between $20 \%-35 \%$ by weight of the original production feedstock. The amount of the pomace generated and its composition will depend on the variety of the apple and the techniques used in extracting the juice [14]. Apple pomace is a potential source of carbohydrate, fibre, polyphenolics and pectin [15] [16] which find application in the food, feed, pharmaceutical, cosmetics, chemical, and biofuels sectors [17]. The major polyphenolic compounds found in apples include; Epicatechins, Procyanidins, Phloridzin, Quercetin conjugates and Chlorogenic acids. 


\section{Materials and Methods}

\subsection{Apple Pomace}

The apple pomace sample composed of 7 varieties of cider apples made of Harry Masters Jersey, Yarlinton Mill, Michelin, Dabinett, Brown Snout, Vilberie and Chisel Jersey, and were collected from Universal Beverages Limited (UBL), Ledbury owned by Heineken international. The apple pomace residues were mixed rigorously to obtain mixture characteristic of the original pomace sample and divided into parts and stored in freezer bags at $-20^{\circ} \mathrm{C}$ till further investigations.

\subsection{Chemical Reagents}

All chemical standards and solvents employed in this investigation were ordered at the highest grade of purity from suppliers indicated in the methodologies. Acetonenitrile, and glacial acetic acid were obtained from Fisher Scientific (UK).

\subsection{Dry Weight Content of Apple Pomace}

A bench top laboratory convention oven $\left(103^{\circ} \mathrm{C} \pm 3^{\circ} \mathrm{C}\right)$ from STATUS International, UK was used for dry weight content. The American Oil Chemist Society (AOCS) standard procedure was utilised to determine the dry matter content, and the results were expressed as the percentage of total fresh weight of the apple pomace as received.

\subsection{Apple Pomace Sample Preparation}

The apple pomace samples were freeze dried using a vacuum freeze dryer EQ03 (Vacuum and Industrial products). The dried pomace samples from the freeze dryer were placed in desiccator for 30 minutes for samples to return to ambient conditions. Freeze dried pomace residue was pulverised using a domestic Moulinex blender 530 (KEMAEU, France). The blending machine was stopped intermittently after every 20 seconds of milling and the pomace powder packed in dark plastic bags and stored in a cool dry place for subsequent use.

\subsection{Extraction of Polyphenolic Compounds from Freeze-Dried Apple Pomace}

Known weight of homogenised freeze dried apple pomace was weighed into 100 $\mathrm{ml}$ Duran bottles and acetone was added $1 \%-8 \%(\mathrm{w} / \mathrm{v})$ solid-to-solvent ratio and the bottle tightly covered. Extractions were done in an incubator Max Q 4000 series benchtop shaker (Thermo Scientific). Extraction temperatures and time were set and shaking $(150 \mathrm{rpm})$ and automatically stops when extraction time elapses. Extracts rich in polyphenolic compounds were transferred into 50 $\mathrm{ml}$ centrifuge tubes and centrifuged in Juan $\mathrm{C} 4 \mathrm{I}$ at $4000 \mathrm{~g}$ for 10 minutes. Supernatant volumes were recorded stored at $-20^{\circ} \mathrm{C}$. Extractions at $60^{\circ} \mathrm{C}$ and $85^{\circ} \mathrm{C}$ were done within Grant OLS200 water bath. 


\subsection{Experimental Design for Optimization of Acetone Mediated Extraction}

The design of the experiments was done similar to the procedure previously described in [18]. The design was composed of one factor at a time (OFAT) experiments and the overall design by response surface methodology (RSM). Solvent concentration $(\%,(\mathrm{v} / \mathrm{v}))$, solid-to-solvent ratio $(1 \%-8 \%(\mathrm{w} / \mathrm{v}))$, temperature and extraction time influenced the recovery of polyphenolic compounds. Stat-Ease Design Expert software 7.0, was employed to set up experiments with varying independent variables, utilising the central composite rotatable design (CCRD). In all, thirty (30) experimental runs consisting of 16 trials for factorial points, 8 runs for axial points and 6 duplicates run around the central point (Table 1).

Table 1. Experimental design by central composite rotatable design using 4 factors.

\begin{tabular}{|c|c|c|c|c|}
\hline Run order & A-acetone conc. $\%(v / v)$ & B-Temp ${ }^{\circ} \mathrm{C}$ & C-Solid/Solvent ratio. \% (w/v) & $\mathrm{D}$-Time, $\min$ \\
\hline 1 & 40.0 & 60.0 & 1.0 & 90.0 \\
\hline 2 & 60.0 & 35.0 & 1.0 & 60.0 \\
\hline 3 & 40.0 & 10.0 & 8.0 & 90.0 \\
\hline 4 & 40.0 & 10.0 & 1.0 & 90.0 \\
\hline 5 & 60.0 & 35.0 & 4.5 & 60.0 \\
\hline 6 & 40.0 & 60.0 & 8.0 & 30.0 \\
\hline 7 & 100.0 & 35.0 & 4.5 & 60.0 \\
\hline 8 & 40.0 & 10.0 & 8.0 & 30.0 \\
\hline 9 & 60.0 & 35.0 & 4.5 & 60.0 \\
\hline 10 & 20.0 & 35.0 & 4.5 & 60.0 \\
\hline 11 & 40.0 & 10.0 & 1.0 & 30.0 \\
\hline 12 & 40.0 & 60.0 & 8.0 & 90.0 \\
\hline 13 & 60.0 & 10.0 & 4.5 & 60.0 \\
\hline 14 & 60.0 & 35.0 & 11.5 & 60.0 \\
\hline 15 & 80.0 & 60.0 & 8.0 & 90.0 \\
\hline 16 & 60.0 & 35.0 & 4.5 & 5.0 \\
\hline 17 & 80.0 & 10.0 & 8.0 & 30.0 \\
\hline 18 & 60.0 & 35.0 & 4.5 & 60.0 \\
\hline 19 & 80.0 & 10.0 & 8.0 & 90.0 \\
\hline 20 & 80.0 & 60.0 & 1.0 & 30.0 \\
\hline 21 & 60.0 & 35.0 & 4.5 & 120.0 \\
\hline 22 & 80.0 & 60.0 & 1.0 & 90.0 \\
\hline 23 & 80.0 & 60.0 & 8.0 & 30.0 \\
\hline 24 & 60.0 & 35.0 & 4.5 & 60.0 \\
\hline 25 & 60.0 & 35.0 & 4.5 & 60.0 \\
\hline 26 & 60.0 & 85.0 & 4.5 & 60.0 \\
\hline 27 & 80.0 & 10.0 & 1.0 & 90.0 \\
\hline 28 & 80.0 & 10.0 & 1.0 & 30.0 \\
\hline 29 & 40.0 & 60.0 & 1.0 & 30.0 \\
\hline 30 & 60.0 & 35.0 & 4.5 & 60.0 \\
\hline
\end{tabular}




\subsection{Identification and Quantification of Polyphenolic Compounds by High Performance Liquid Chromatography (HPLC)}

High performance liquid chromatographic (HPLC) procedure in a reverse mode, previously published in literature was used to separate phenolic compounds [19]. Polyphenolic compounds in extracts were resolved using an Agilent 1100 series HPLC system with DAD-UV detector linked to a Chemstation software. The column used was Prodigy $5 \mu \mathrm{m}$ ODS3 100A, C18 $(250 \times 4.6 \mathrm{~mm}$ I.D) from Phenomenex (Torrance, CA, USA) with a guard column operated at $40^{\circ} \mathrm{C}$. Eluent $\mathrm{A}$ of the mobile phase was composed of $2 \%(\mathrm{v} / \mathrm{v})$ of glacial acetic acid in water. Eluent B consisted of $0.5 \%$ of acetic acid in 50/50 (v/v) of water and acetonitrile. Pure acetonitrile (100\%) was the Eluent C. The injection volume was $10 \mu \mathrm{l}$ per sample and the solvent gradient systems for the separations was as follows: starting with $10 \%$ of B and increasing the gradient to $55 \% \mathrm{~B}$ in 50 minutes. Further increase from 55\% B to $100 \%$ B was done in 10 minutes and finally decreased from $100 \%$ B to the initial $10 \%$ B in 5 minutes. Eluent $C$ was used to recondition the column under isocratic flow by pumping $100 \%$ acetonitrile for 10 minutes, and $10 \% \mathrm{~B}$ also for 10 minutes. The flow rate was $1 \mathrm{ml} / \mathrm{min}$ and polyphenolic compounds were monitored at $280 \mathrm{~nm}$ for flavanols, $320 \mathrm{~nm}$ for hydrocinnamic acid and $370 \mathrm{~nm}$ for flavonols. Retention times and spectra data were collected.

\subsection{Preparation of Phenolic Standard}

Stock solutions ( $1 \mathrm{mg} / \mathrm{ml}$ ) of Chlorogenic acid ( $\geq 95 \%)$, (-) Epicatechin ( $\geq 90 \%)$, \pm Catechin hydrate, Phloridzin dihydrate $(\geq 99 \%)$, Procyanidin B2 $(\geq 90 \%)$, Quercetin-3- $\beta$-D-glucoside ( $\geq 90 \%)$, Quercetin-3-D-galactoside ( $\geq 97 \%)$ Phloretin, in Chromasolv for HPLC (Sigma-Aldrich, UK). The stock solutions were diluted appropriately $(0.01-1 \mathrm{mg} / \mathrm{ml})$ and injected in triplicates into the HPLC equipment. Calibration curves were constructed and quantification of polyphenolic compounds in samples was derived from the calibration curves of corresponding standards.

\section{Results and Discussion}

The mean dry matter content of the homogenized cider apple pomace under this investigation was $27.7 \pm 0.3 \mathrm{~g} / 100 \mathrm{~g}$ fresh weight. Dry weight value reported for apple pomace in literature ranges, from 21.8 - $33.6 \mathrm{~g} / 100 \mathrm{~g}$ [20] [21] [22]. Mean dry matter content of the freeze dried apple pomace was $28.3 \pm 0.6 \mathrm{~g} / 100 \mathrm{~g}$ fresh weight.

\subsection{Identification and Quantification of Phenolic Compounds in Extracts}

The polyphenolic compounds in the extracts were identified by comparing retention times $\left(t_{R}\right)$ and spectra data at maximum absorbance with known phenolic standards. Chlorogenic acid, Caffeic acid, Epicatechin, Procyanidin B, Quer- 
cetin-3-galactoside and Quercetin-3-glucoside and Phloridzin, were found to be present in the extracts. These phenolic compounds were identified in industrial apple pomace and documented in literature [4] [19] [23] [24] [25]. The chromatogram of the aqueous acetone extract of the phenolic compounds at $320 \mathrm{~nm}$ is shown (Figure 1).

The calibration equations, derived from the plots of concentrations of phenolic standard versus the chromatographic peak areas are shown in Table 2. Concentrations of phenolic compounds $(\mathrm{mg} / \mathrm{kg})$ dry weight of apple pomace of various design combinations were obtained from the regression equations of corresponding standards and reported (Table 3 ).

\subsection{Model Selection}

A number of modelling options were explored for possible selection, including two factor interactions, quadratic and cubic models. These were tested to select

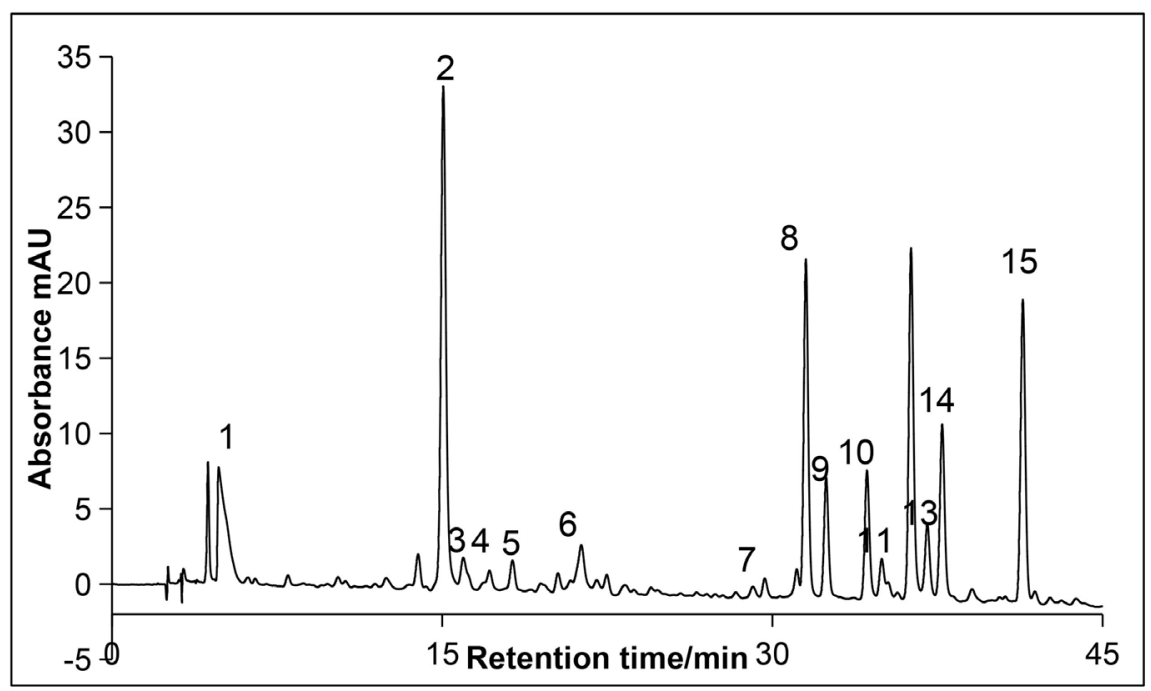

Figure 1. Chromatogram $(320 \mathrm{~nm})$ of the extract from the cider apple pomace in aqueous acetone. 1 = solvent peak (acetone), 2 = chlorogenic acid, $3=$ procyanidin $\mathrm{B} 2,4=$ caffeic acid, 5 = epicatechin, 7-Ferulic acid, 8 = quercetin-3-galactoside, 9 = quercetin-3-glucoside, $15=$ phloridzin

Table 2. Equations for calibration of standard phenolic compounds from HPLC.

\begin{tabular}{ccc}
\hline Phenolic Standard & Regression equation & Correlation Coefficient $\left(R^{2}\right)$ \\
\hline Chlorogenic acid & $y=25667 x$ & 0.9992 \\
Procyanidin B2 & $y=4.9706 x$ & 0.9833 \\
Quercetin-3-galactoside & $y=26.232 x$ & 0.9998 \\
Quercetin-3-glucoside & $y=13829 x$ & 1.0000 \\
Phloridzin & $y=14704 x$ & 0.9999 \\
Epicatechin & $y=6210 x$ & 0.9998 \\
Catechin & $y=5901.3 x$ & 1.0000
\end{tabular}


Table 3. Concentration of phenolic compounds $(\mathrm{mg} / \mathrm{kg})$ dry weight of the cider apple pomace.

\begin{tabular}{|c|c|c|c|c|c|c|}
\hline $\begin{array}{c}\text { Std } \\
\text { Order }\end{array}$ & CGA & PHL & Q-3-gal & Q-3-glu & E-CAT & Pr-B2 \\
\hline 1 & $183.17 \pm 4.7$ & $686.35 \pm 21.5$ & $159.99 \pm 2.4$ & $111.14 \pm 2.6$ & ND & ND \\
\hline 15 & $170.85 \pm 4.0$ & $545.01 \pm 10.6$ & $128.88 \pm 1.9$ & $89.45 \pm 1.7$ & $142.50 \pm 9.4$ & $216.85 \pm 11.8$ \\
\hline 19 & $187.78 \pm 7.1$ & $677.32 \pm 17.1$ & $171.33 \pm 0.5$ & $115.22 \pm 3.0$ & $130.30 \pm 10.8$ & $201.55 \pm 19.8$ \\
\hline 22 & $160.99 \pm 5.7$ & $562.13 \pm 18.9$ & $142.92 \pm 4.7$ & $98.83 \pm 3.7$ & $132.9 \pm 9.7$ & $208.33 \pm 1.1$ \\
\hline 16 & $201.80 \pm 8.7$ & $722.53 \pm 25.3$ & $175.09 \pm 8.2$ & $117.74 \pm 4.7$ & $193.6 \pm 33.1$ & $165.80 \pm 26.0$ \\
\hline 23 & $191.88 \pm 5.9$ & $634.49 \pm 15.9$ & $174.67 \pm 0.4$ & $117.84 \pm 2.5$ & $141.5 \pm 8.0$ & $227.81 \pm 4.4$ \\
\hline 6 & $177.39 \pm 12.2$ & $641.86 \pm 37.7$ & $174.10 \pm 12.6$ & $116.91 \pm 7.6$ & $173.2 \pm 37.9$ & $140.35 \pm 28.3$ \\
\hline 26 & $190.15 \pm 6.8$ & $693.36 \pm 20.8$ & $177.78 \pm 0.3$ & $118.84 \pm 3.3$ & $140.7 \pm 10.7$ & $451.69 \pm 22.4$ \\
\hline 14 & $175.36 \pm 7.6$ & $636.60 \pm 23.2$ & $173.16 \pm 8.1$ & $116.47 \pm 4.7$ & $167.4 \pm 32.8$ & $150.40 \pm 23.3$ \\
\hline 20 & $157.05 \pm 22.0$ & $776.84 \pm 52.9$ & $176.32 \pm 18.2$ & $134.37 \pm 0.0$ & $\mathrm{ND}$ & ND \\
\hline 11 & $221.58 \pm 9.0$ & $785.27 \pm 30.8$ & $186.58 \pm 6.1$ & $128.20 \pm 2.5$ & $\mathrm{ND}$ & $\mathrm{ND}$ \\
\hline 21 & $184.12 \pm 10.9$ & $813.70 \pm 31.9$ & $187.83 \pm 7.1$ & $131.44 \pm 6.7$ & ND & ND \\
\hline 13 & $146.69 \pm 6.2$ & $484.60 \pm 20.6$ & $133.68 \pm 5.3$ & $92.88 \pm 3.8$ & $132.2 \pm 9.1$ & $210.25 \pm 5.7$ \\
\hline 9 & $167.89 \pm 8.7$ & $723.64 \pm 36.7$ & $162.88 \pm 7.8$ & $114.46 \pm 5.9$ & ND & ND \\
\hline 28 & $191.38 \pm 8.4$ & $713.80 \pm 5.7$ & $181.05 \pm 1.3$ & $121.81 \pm 4.4$ & $152.5 \pm 20.0$ & $224.06 \pm 3.1$ \\
\hline 7 & $162.72 \pm 10.6$ & $588.53 \pm 6.9$ & $135.03 \pm 1.4$ & $93.17 \pm 1.2$ & $141.7 \pm 5.9$ & $216.38 \pm 12.8$ \\
\hline 18 & $34.49 \pm 4.2$ & $273.55 \pm 33.1$ & $30.34 \pm 6.5$ & $29.22 \pm 0.0$ & ND & ND \\
\hline 5 & $156.00 \pm 3.5$ & $516.75 \pm 12.2$ & $136.02 \pm 2.7$ & $94.57 \pm 2.1$ & $133.1 \pm 6.9$ & $218.26 \pm 9.0$ \\
\hline 25 & $191.19 \pm 5.5$ & $727.07 \pm 12.3$ & $176.54 \pm 3.3$ & $122.26 \pm 2.7$ & $132.5 \pm 4.0$ & $217.18 \pm 5.4$ \\
\hline 17 & $140.67 \pm 0.9$ & $314.72 \pm 4.2$ & $147.77 \pm 0.8$ & $103.45 \pm 1.0$ & $109.9 \pm 1.6$ & $207.83 \pm 10.1$ \\
\hline 24 & $191.99 \pm 2.9$ & $707.97 \pm 18.1$ & $178.16 \pm 1.9$ & $119.19 \pm 2.2$ & $157.82 \pm 10.7$ & $222.60 \pm 2.1$ \\
\hline 12 & $168.67 \pm 14.8$ & $894.62 \pm 62.4$ & $172.08 \pm 15.4$ & $119.92 \pm 0.0$ & ND & ND \\
\hline 8 & $190.21 \pm 11.3$ & $717.27 \pm 28.7$ & $173.37 \pm 8.1$ & $116.41 \pm 4.3$ & $193.27 \pm 19.3$ & $167.11 \pm 28.0$ \\
\hline 30 & $200.41 \pm 3.1$ & $705.85 \pm 14.4$ & $182.74 \pm 1.6$ & $125.56 \pm 1.4$ & $148.98 \pm 0.2$ & $225.72 \pm 6.0$ \\
\hline 29 & $193.29 \pm 2.5$ & $709.51 \pm 13.0$ & $184.98 \pm 1.9$ & $120.09 \pm 1.1$ & $142.30 \pm 1.8$ & $212.80 \pm 0.6$ \\
\hline 20 & $248.06 \pm 4.7$ & $784.18 \pm 20.2$ & $180.15 \pm 1.7$ & $120.74 \pm 2.1$ & $264.15 \pm 30.0$ & $339.78 \pm 18.7$ \\
\hline 10 & $143.60 \pm 13.7$ & $845.59 \pm 67.5$ & $164.39 \pm 14.0$ & $\mathrm{ND}$ & ND & ND \\
\hline 2 & $124.51 \pm 11.6$ & $847.53 \pm 64.9$ & $173.26 \pm 11.8$ & $\mathrm{ND}$ & ND & $\mathrm{ND}$ \\
\hline 3 & $189.90 \pm 0.9$ & $674.83 \pm 44.2$ & $149.79 \pm 0.9$ & $104.02 \pm 1.4$ & ND & ND \\
\hline 27 & $192.57 \pm 3.0$ & $682.51 \pm 15.8$ & $175.66 \pm 1.7$ & $121.14 \pm 1.6$ & $138.97 \pm 5.2$ & $216.97 \pm 3.1$ \\
\hline
\end{tabular}

Std = standard, CGA-Chlorogenic acid; PHL-Phloridzin; Q-3-gal-Quercetin-3-galatoside; Q-3-glu-Quercetin3-glucoside; E-CAT-Epicatechin; Pr-B2-Procyanidin B2; ND not detected.

suitable model that best fits, and capable of depicting the real time response of the surface. For a given model to be appropriate, then it should be significant $(\mathrm{P}$ $<0.05)$ and an insignificant lack of fit $(\mathrm{P}>0.05)$. Analysis of variance (ANOVA) 
at $95 \%$ confidence interval were performed utilising Stat-Ease software on the data shown in Table 3, to study the influence of the solvent concentration, solid to solvent ratio, temperature and extraction time on overall recovery of the responses. The results obtained were fitted into a generalised second order polynomial model as in (1):

$$
Y=\beta_{0}+\sum_{i=1}^{4} \beta_{i} x_{i}+\sum_{i=1}^{4} \beta_{i i} x_{i}^{2}+\sum \sum_{i<j=1}^{4} \beta_{i j} x_{i} x_{j}
$$

where $Y$ is the measured response, $\beta_{0} \quad \beta_{i} \quad \beta_{i i}$ and $\beta_{i j}$ are regression coefficients for intercept, linear, quadratic and interaction terms respectively and $x_{i}$ and $x_{j}$ are coded design variables. Selected models for phenolic compounds were significant $(\mathrm{P}<0.05)$ and insignificant lack of fit $(\mathrm{P}>0.05)$, except for Chlorogenic acid Quercetin 3-glucoside which had significant lack of fit ( $\mathrm{P}<$ 0.05). All models had satisfactory level of adequacies with coefficients of regression $R^{2}>0.9000$, meaning more than $90 \%$ of the data generated can be explained by the predictive models. Adjusted correlation coefficients $R_{\text {Adj }}^{2}$ reasonable agrees with predicted correlation coefficient $R_{P r i}^{2}$. Coefficients of variation were $<5 \%$ for each determination at the $95 \%$ confidence interval. The yields of polyphenolic compounds were significantly affected by acetone concentration, solid-to-solvent ratio, temperature in addition to their interactions. Summary of the analysis of variance (ANOVA) of quantified phenolic compounds is shown in Table 4.

\subsubsection{Predictive Model for Extraction of Chlorogenic Acid}

Concentration of Chlorogenic acid in extracts varied from 124.5 to $221.58 \mathrm{mg} / \mathrm{kg}$ dry weight of the apple pomace with mean concentration of $176.24 \mathrm{mg} / \mathrm{kg}$. The predictive model in terms of actual factors is shown in Equation (2).

Chlorogenic Acid $=+100.52918+3.21207 A+0.29177 B-6.15519 C$

$$
\begin{aligned}
& +3.24996 \times 10^{-3} D+0.24195 A C-0.038655 B C+5.36020(2) \\
& \times 10^{-3} B D-0.026760 C D-0.037565 A^{2}-0.56300 C^{2}
\end{aligned}
$$

\begin{tabular}{|c|c|c|c|c|c|c|c|c|c|c|c|c|}
\hline \multirow{2}{*}{ Response } & \multicolumn{12}{|c|}{ Significance level $(\mathrm{p}<0.05)$} \\
\hline & $A$ & $B$ & $C$ & $D$ & $A C$ & $A D$ & $B C$ & $B D$ & $C D$ & $A^{2}$ & $B^{2}$ & $C^{2}$ \\
\hline CGA & $\checkmark$ & $\checkmark$ & & & $\checkmark$ & & & $\checkmark$ & & $\checkmark$ & & $\checkmark$ \\
\hline PHL & $\checkmark$ & $\checkmark$ & $\checkmark$ & $\checkmark$ & & & $\checkmark$ & $\checkmark$ & $\checkmark$ & $\checkmark$ & & $\checkmark$ \\
\hline Q-gal & $\checkmark$ & & $\checkmark$ & & $\checkmark$ & $\checkmark$ & & $\checkmark$ & & & $\checkmark$ & \\
\hline Q-glu & $\checkmark$ & $\checkmark$ & $\checkmark$ & & $\checkmark$ & & & & & $\checkmark$ & & $\checkmark$ \\
\hline $\operatorname{Pr}-\mathrm{B} 2$ & $\checkmark$ & $\checkmark$ & $\checkmark$ & & $\checkmark$ & $\checkmark$ & & & & $\checkmark$ & & $\checkmark$ \\
\hline E-CAT & $\checkmark$ & $\checkmark$ & $\checkmark$ & & & & & & & & & $\checkmark$ \\
\hline TPC-HPLC & & $\checkmark$ & $\checkmark$ & & $\checkmark$ & & & & $\checkmark$ & $\checkmark$ & & $\checkmark$ \\
\hline
\end{tabular}

Table 4. Significance of design factors and interaction terms on responses. 
Chlorogenic acid is polar within polyphenolic compounds and recovery from plant sources require a certain reasonable level of polarity of the solvent. An increase in temperature from $10^{\circ} \mathrm{C}$ to $60^{\circ} \mathrm{C}$ for $1 \%$ solid-solvent ratio for acetone concentration of $40 \%(\mathrm{v} / \mathrm{v})$, caused yield of Chlorogenic acid to increase by $14 \%$, but decreases by approximately $20 \%$ as concentration of acetone approaches $80 \%(\mathrm{v} / \mathrm{v})$. concentration of acetone $52 \%(\mathrm{v} / \mathrm{v})$ at $40^{\circ} \mathrm{C}$ was reported as good for recovering Chlorogenic acid from apple pomace [26]. The current investigation revealed $46 \%(\mathrm{v} / \mathrm{v})$ of acetone at $60^{\circ} \mathrm{C}$ as good for extracting Chlorogenic acid from the cider apple pomace. Therefore, decreasing the concentration of acetone and increasing temperature favours yield of Chlorogenic acid. Optimal concentration $(206.3 \mathrm{mg} / \mathrm{kg}$ dry weight of apple pomace) of Chlorogenic acid was recovered and was within the range $(30-1766 \mathrm{mg} / \mathrm{kg}$ ) reported for selected cider apples [23]. The variation of design parameters and Chlorogenic acid is shown in Figure 2.

\subsubsection{Predictive Model for Extraction of Phloridzin}

The concentration of Phloridzin in extracts ranged from $314.7 \mathrm{mg} / \mathrm{kg}$ to 894.6 $\mathrm{mg} / \mathrm{kg}$. The results were consistent with what has been published previously ( 25 $\mathrm{mg} / \mathrm{kg}$ to $1061 \mathrm{mg} / \mathrm{kg}$ ) of cider apples [23]. The model equation based on the regression analysis in terms of actual factors is shown in Equation (3).

$$
\begin{aligned}
\text { Phloridzin }= & +106.89513+21.36305 A-1.01061 B-59.51068 C \\
& +0.81180 D+0.18934 B C+0.016002 B D-0.20193 C D \\
& -0.14966 A^{2}+4.52601 C^{2}
\end{aligned}
$$

Phloridzin concentration increased by $16 \%$ at $1 \%$ solid -solvent ratio as the acetone concentration was increased to $80 \%(\mathrm{v} / \mathrm{v})$, and decreased by $24 \%$ as solid-solvent ratio approaches $8 \%$. Temperature had minimal effect on the recovery

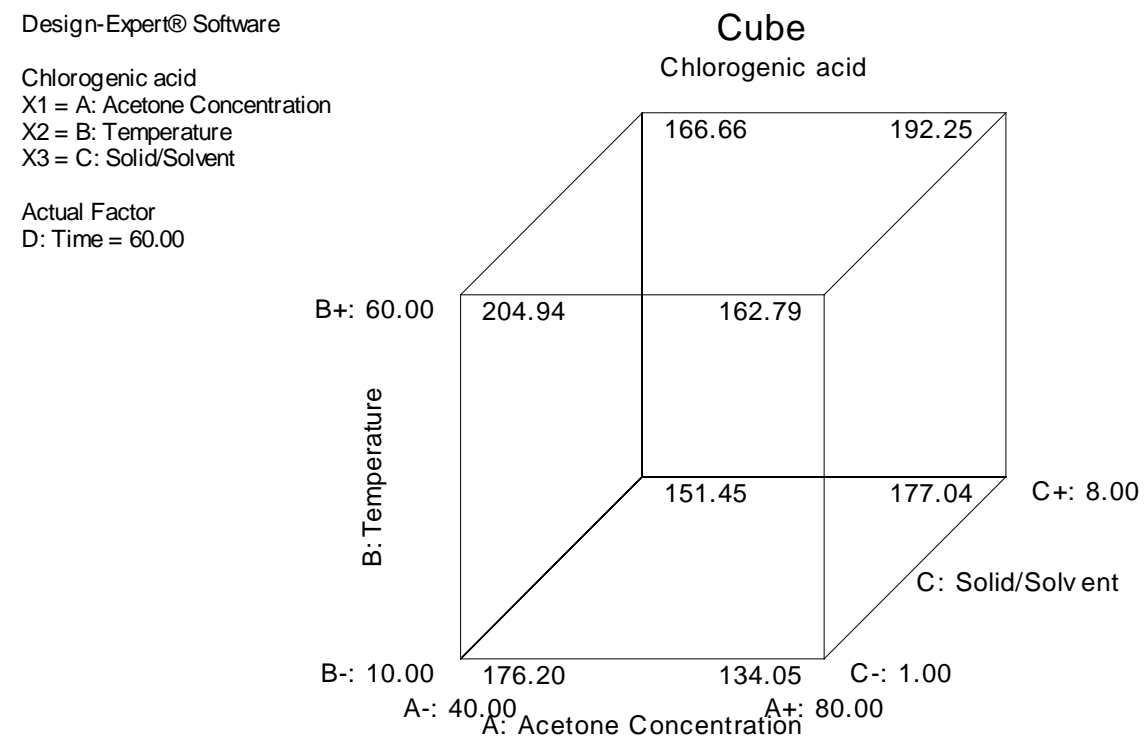

Figure 2. Effects of acetone concentration (\% v/v), temperature $\left({ }^{\circ} \mathrm{C}\right)$ and solid-to-solvent ratio $(\% \mathrm{w} / \mathrm{v})$ of cider apple pomace on the concntration of Chlorogenic acid $(\mathrm{mg} / \mathrm{kg})$ for 60 minute extraction time. 
of the dihydrochalcone as it only increased by about $1 \%$ when temperature was increased from $10^{\circ} \mathrm{C}$ to $60^{\circ} \mathrm{C}$ as shown in Figure 3 .

Optimal concentration of Phloridzin $(858.92 \mathrm{mg} / \mathrm{kg}$ ) was achieved using $73 \%$ (v/v) acetone at $60^{\circ} \mathrm{C}$ for 60 minutes as against $75 \%(\mathrm{v} / \mathrm{v})$ at $40^{\circ} \mathrm{C}$ for 60 minutes reported earlier [26].

\subsubsection{Predictive Model for Extraction of Quercetin Glycosides}

Quercetin-3-galactoside dominates among other quercetin glycosides in apple peels [27] and ranged in the extracts from $133.7-187.8 \mathrm{mg} / \mathrm{kg}$ dry weight of apple pomace with mean concentration of $168.6 \mathrm{mg} / \mathrm{kg}$. Quercetin-3-glucoside ranged in extracts from $60-128.2 \mathrm{mg} / \mathrm{kg}$. Both results agreed with previous reports $(50-520 \mathrm{mg} / \mathrm{kg}$ ) for Quercetin-3-galactoside, and $(9-152 \mathrm{mg} / \mathrm{kg})$ of quercetin-3-glucoside in cider apples [23]. Transformed quadratic models excluding outliers were appropriate and described the behaviour of the Quercetin glycosides when the design factors were varied. The model equations are shown in Equation (4) and Equation (5).

$$
\begin{aligned}
& \frac{1.0}{\text { Sqrt }(Q-\text { gal })} \\
= & +0.086163-1.15229 \times 10^{-4} A-3.72357 \times 10^{-4} B+2.1303710^{-3} C \\
& -6.64449 \times 10^{-5} D-2.7551 \times 10^{-5} A C+1.52022 \times 10^{-6} A D \\
& -1.13192 \times 10^{-6} B D+6.07617 \times 10^{-6} B^{2}
\end{aligned}
$$

$$
\begin{aligned}
& \frac{1.0}{\text { Sqrt }(Q-\text { glu })} \\
& =+0.099931-4.32652 \times 10^{-4} A+1.64815 \times 10^{-3} C-1.0606 \\
& \times 10^{-4} D-1.5 \times 4954610^{-4} A C+1.76547 \times 10^{-6} A D \\
& +1.06599 \times 10^{-5} A^{2}+6.69141 \times 10^{-4} C^{2}
\end{aligned}
$$

Design-Expert $\circledast$ Software

Phloridzin

$\mathrm{X} 1=\mathrm{A}:$ Acetone Concentration

$\mathrm{X} 2=\mathrm{B}:$ Temperature

$\mathrm{X} 3=\mathrm{C}:$ Solid/Solvent

Actual Factor

D: Time $=60.00$
Cube

Phloridzin

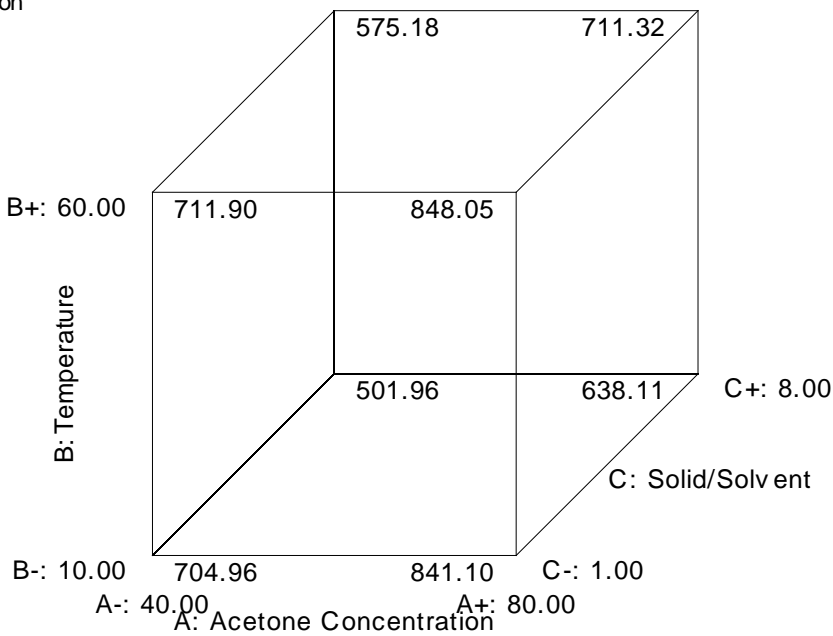

Figure 3. Effects of acetone concentration $\%(\mathrm{v} / \mathrm{v})$, temperature $\left({ }^{\circ} \mathrm{C}\right)$ and solid-to-solvent ratio $(\% \mathrm{w} / \mathrm{v})$ of the cider apple pomace on the concentration of Phloridzin $(\mathrm{mg} / \mathrm{kg})$ for 60 minutes extraction time. 
Quercetin-3-galactoside concentration increased by $5.24 \%$ when concentration of acetone was raised to $80 \%(\mathrm{v} / \mathrm{v})$ and slightly when temperature increases from $10^{\circ} \mathrm{C}-60^{\circ} \mathrm{C}$ with increasing solid-to-solvent ratio as reflected in Figure 4. Interaction between acetone concentration and solid-to solvent ratio (AC) was more significant than between temperature and time $(\mathrm{BD})$ as revealed by their negative coefficient values which was higher in $\mathrm{AC}\left(2.7551 \times 10^{-5}\right)$ than $\mathrm{BD}$ $\left(1.13192 \times 10^{-6}\right)$. The negative coefficient values of temperature and time as well as their interaction suggested overtime with increasing temperature, less recovery of the glycoside could be recovered as shown in Figure 4. Decrease in concentration of the glycoside may be due to degradation or hydrolysis of the sugar moieties attached to the quercetin aglycone. Similar results were reported during ultra-sonication procedure of solvent extraction of Quercetin glycosides from "Idared" apple peels [28].

Optimal acetone concentration of $76 \%(\mathrm{v} / \mathrm{v})$ with $6 \%$ solid-to-solvent ratio was good for extracting quercetin-3-galactoside at $41^{\circ} \mathrm{C}$ for 58 minutes extraction time. A predicted concentration of $189 \mathrm{mg} / \mathrm{kg}$ of quercetin-3-galactoside was suggested for best desirability at the optimal conditions.

Quercentin-3-glucoside showed different behaviour with extraction parameters (Figure 5) compared to Quercetin-3-galactoside (Figure 4) although both are classified as quercetin glycosides. Both glycosides interacted differently with experimental factors. Solid-to-solvent ratio term influenced positively the yield of quercetin-3-glucoside whereas temperature controlled the elution of quercetin-3-galoctoside in extracts.

The optimal conditions for extracting Quercetin-3-glucoside using aqueous acetone from the apple pomace were $40 \%(\mathrm{v} / \mathrm{v})$ acetone, 3.5\% solid-to solvent

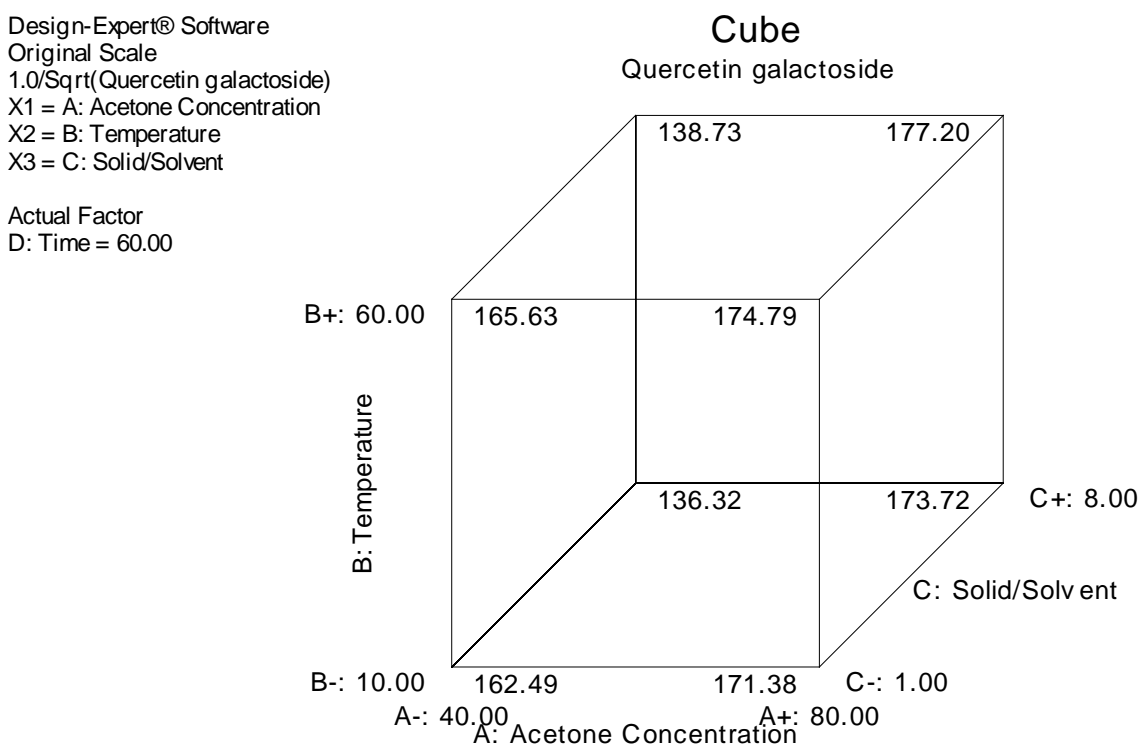

Figure 4. The effects of temperature $\left({ }^{\circ} \mathrm{C}\right)$, acetone concentration $\%(\mathrm{v} / \mathrm{v})$ and solid-to-solvent ratio $\%(\mathrm{w} / \mathrm{v})$ on the concentration of quercetin-3-galactoside $(\mathrm{mg} / \mathrm{kg})$ for 60 minutes extraction time. 


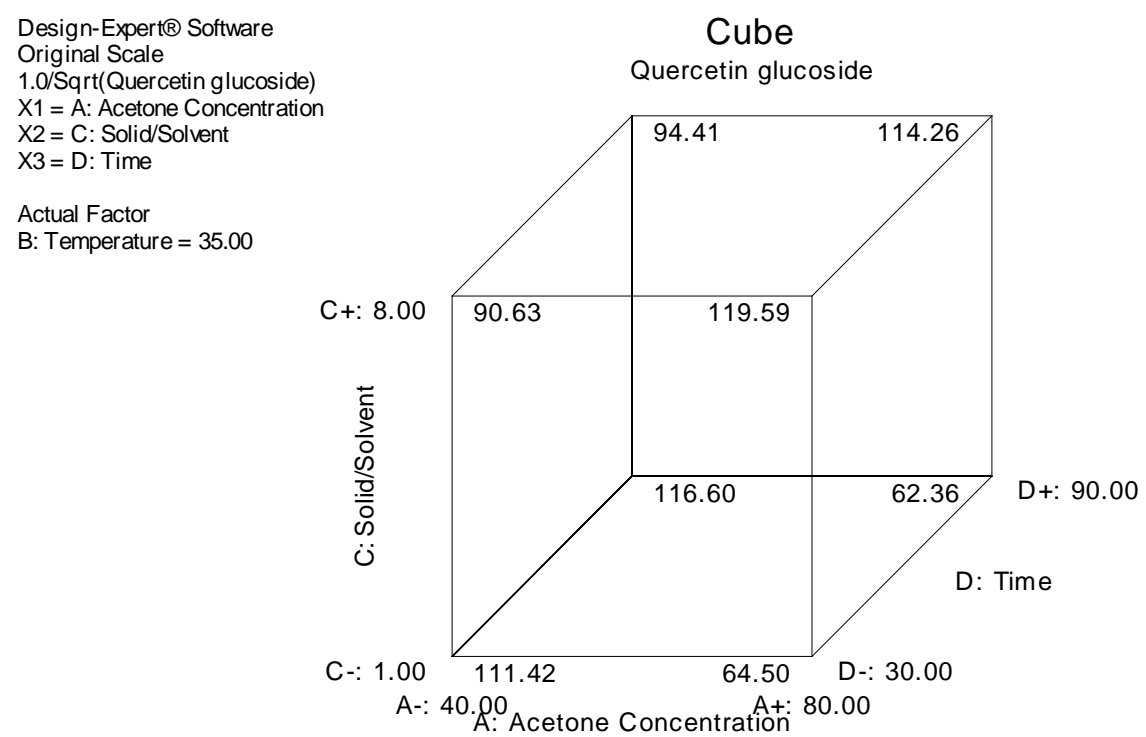

Figure 5. Effects of acetone concentration \% (v/v), time (minutes) and solid-to solvent ratio $\%(\mathrm{w} / \mathrm{v})$ on the concentration of quercetin-3-glucooside at temperature $35^{\circ} \mathrm{C}$.

ratio for 31 minutes at $23^{\circ} \mathrm{C}$ extraction temperature. These optimal conditions were different for predicted conditions for recovering quercetin-3-galactoside from the apple peels. It is very important to emphasise that there are no data available in literature to the best of our knowledge as regards good extraction parameters for extracting Quercetin glycosides from cider apple pomace using acetone as an extraction solvent.

\subsubsection{Predictive Model for Extraction of Epicatechin}

Epicatechin, is a major flava-3-ol, in selected cider apples with concentration in extract ranging from $0-193 \mathrm{mg} / \mathrm{kg}$. Similarly, $46 \mathrm{mg} / \mathrm{kg}$ to $2225 \mathrm{mg} / \mathrm{kg}$ had been reported in fresh cider apples [23]. The regression analysis predicted model equation as shown in Equation (6) and the variation of design parameters with epicatechin concentration shown in Figure 6.

$$
\begin{aligned}
\text { Epicatechin }= & -53.92179-0.12460 A-0.037316 B+56.08802 C \\
& +0.16379 A C+0.051178 B C-5.00284 C^{2}
\end{aligned}
$$

\subsubsection{Predictive Model for Extraction of Procyanidin B2 under Acetone} Molecular and structural differences within Proanthocyannidins make their extraction and quantification very challenging. Their complexation with other non-soluble polymers underestimates their quantification due to incomplete extraction [29]. About 50\% - 93\% of apple Procyanidins may be retained within cell wall material during processing of apple juice [30]. Procyanidin B2, is a major representative of the various groups of the proanthocyanidins in apple peels [19] and varied in the extract from 0 (not detectable) to $227.8 \mathrm{mg} / \mathrm{kg}$ with mean concentration of $137.68 \mathrm{mg} / \mathrm{kg}$. Result was consistent with previous reports (56 $\mathrm{mg} / \mathrm{kg}$ to $1362 \mathrm{mg} / \mathrm{kg}$ ) of selected British cider apples [23]. Predicted model equation in terms of actual factors of Procyanidin B2 is shown in Equation (7). 
Design-Expert@ Software

Epicatechin

$\mathrm{X} 1=\mathrm{A}$ : Acetone Concentration

$\mathrm{X} 2=\mathrm{B}:$ Temperature

X3 = C: Solid/Solvent

Actual Factor

D: Time $=60.00$
Cube

Epicatechin

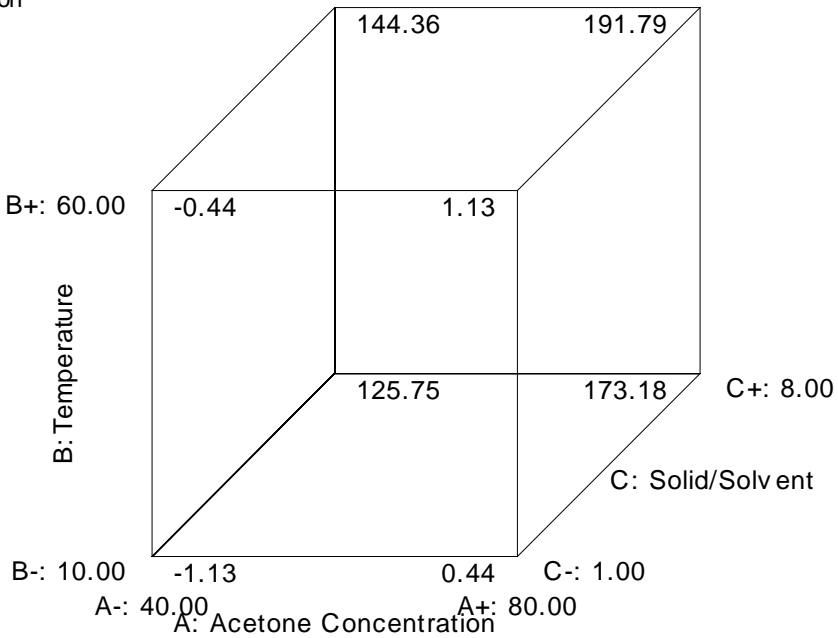

Figure 6. Effects of acetone concentration $\%(\mathrm{v} / \mathrm{v})$, temperature $\left({ }^{\circ} \mathrm{C}\right)$ and solid-to-solvent ratio $\%(\mathrm{w} / \mathrm{v})$ on concntration of epicatechin $(\mathrm{mg} / \mathrm{kg})$ dry weight cidr apple pomace for 60 minutes extraction time.

$$
\begin{aligned}
\text { Procyanidin B2 }= & -182.02469+2.96978 A-0.011758 B+124.61390 C \\
& -0.35523 D-0.21364 A C+0.034340 B C-0.022831 A^{2} \\
& -9.59429 C^{2}+2.80355 \times 10^{-3} B^{2}
\end{aligned}
$$

The variation Procyanidin B2 with experimental factors is shown in Figure 7.

The concentration of Procyanidin B2 increases as solid-solvent ratio, temperature and acetone concentration increases and decreases significantly for further increase in these parameters. Optimal solvent concentration and solid-solvent ratio for extracting Procyanidin $\mathrm{B} 2$ from the apple pomace at $25^{\circ} \mathrm{C}$ for $40 \mathrm{mi}$ nutes were $54 \%(\mathrm{v} / \mathrm{v})$ and $6 \%$ respectively.

\subsection{Effect of Design Variables on Total Phenolic Content by the HPLC Method}

Acetone concentration and solid-to solvent ratio and their interaction was the most significant factors in the recovery of the polyphenolic compounds. The model predicted total phenolic content in terms of actual design factors as in Equation (8)

$$
\begin{aligned}
\mathrm{TPC}= & +320.47139+27.34556 A-0.23484 B+42.73751 C+0.66181 D \\
& +0.67946 A C+0.031083 B D-0.29702 C D-5.91447 A^{2}
\end{aligned}
$$

The case statistics report showing actual values versus those predicted using the model equation is shown in Table 5

The contour plot of the total phenolic content $(\mathrm{mg} / \mathrm{kg})$ quantified by HPLC method is shown in Figure 8.

Acetone concentration and solid-to-solvent ratio significantly affected the overall yields of extraction of polyphenolic compounds. Optimised conditions of 
Design-Expert® Software

Procyanidin B2

$\mathrm{X} 1=\mathrm{A}$ : Acetone Concentration

$\mathrm{X} 2=\mathrm{B}:$ Temperature

X3 = C: Solid/Solvent

Actual Factor

D: Time $=60.00$
Cube

Procy anidin B2

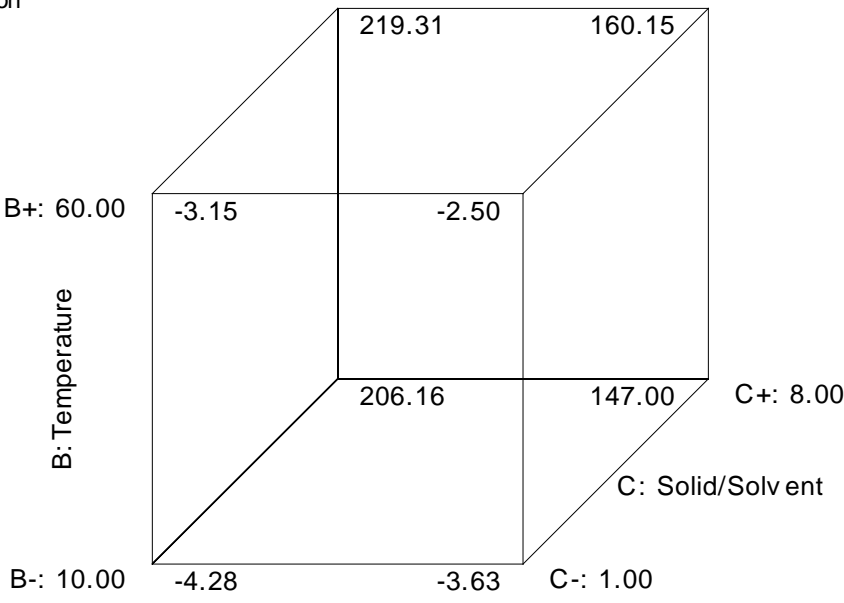

A-: 40.00 A: Acetone Concentration 80.00

Figure 7. Effect of acetone concentration $\%(v / v)$, solid-to-solvent ratio $\%(w / v)$ and temperature $\left({ }^{\circ} \mathrm{C}\right)$ on the amount of Procyanidin B2 $(\mathrm{mg} / \mathrm{kg})$ dry weight for 60 minutes extraction time. of apple pomace.

Design-Expert® Software

TPC/HPLC

- Design Points

1394

960

X1 = A: Acetone Concentration X2 = C: Solid/Solvent

Actual Factors

B: Temperature $=35.00$

D: Time $=60.00$
TPC/HPLC

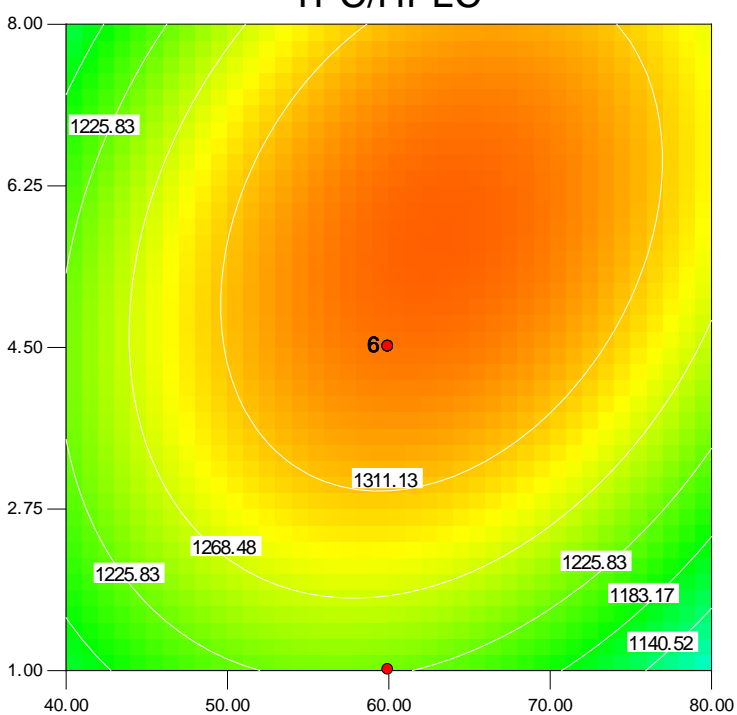

A: Acetone Concentration

Figure 8. Effect of acetone concentration $\%(v / v)$ and solid-to-solvent ratio \% (w/v) on total phenolic content (TPC, $\mathrm{mg} / \mathrm{kg}$ ) of acetone extracts of the apple pomace by the HPLC determination

Table 5. Diagnostic case statistics report of total phenolic content $(\mathrm{mg} / \mathrm{kg})$ dry weight.

\begin{tabular}{ccccc}
\hline Standard Order & Actual Value $(\mathrm{mg} / \mathrm{kg})$ & Predicted Value $(\mathrm{mg} / \mathrm{kg})$ & Residual & Leverage \\
\hline 1 & 1106.00 & 1101.12 & 4.88 & 0.445 \\
2 & 1044.00 & 1036.84 & 7.16 & 0.470 \\
\hline
\end{tabular}




\section{Continued}

\begin{tabular}{|c|c|c|c|c|}
\hline 3 & 1043.00 & 1136.00 & -93.00 & 0.447 \\
\hline 4 & 1103.00 & 1071.72 & 31.28 & 0.469 \\
\hline 5 & 1158.00 & 1155.55 & 2.45 & 0.410 \\
\hline 6 & 1222.00 & 1281.52 & -59.52 & 0.457 \\
\hline 7 & 1219.00 & 1190.43 & 28.57 & 0.417 \\
\hline 8 & 1303.00 & 1316.40 & -13.40 & 0.461 \\
\hline 9 & 1120.00 & 1141.66 & -21.66 & 0.445 \\
\hline 10 & 1046.00 & 1077.38 & -31.38 & 0.470 \\
\hline 11 & 1314.00 & 1269.79 & 44.21 & 0.447 \\
\hline 12 & 1174.00 & 1205.51 & -31.51 & 0.469 \\
\hline 13 & 1073.00 & 1071.34 & 1.66 & 0.410 \\
\hline 14 & 1213.00 & 1197.31 & 15.69 & 0.456 \\
\hline 15 & 1109.00 & 1199.47 & -90.47 & 0.416 \\
\hline 16 & 1366.00 & 1325.44 & 40.56 & 0.460 \\
\hline 17 & 960.00 & 918.88 & 41.12 & 0.73 \\
\hline 19 & 1301.00 & 1304.06 & -3.06 & 0.145 \\
\hline 21 & 1294.00 & 1228.78 & 65.22 & 0.148 \\
\hline 22 & 1167.00 & 1142.19 & 24.81 & 0.74 \\
\hline 23 & 1300.00 & 1322.10 & -22.10 & 0.244 \\
\hline 24 & 1340.00 & 1369.61 & -29.61 & 0.266 \\
\hline 25 & 1354.00 & 1344.82 & 9.18 & 0.097 \\
\hline 26 & 1352.00 & 1344.82 & 7.18 & 0.097 \\
\hline 27 & 1379.00 & 1344.82 & 34.18 & 0.097 \\
\hline 28 & 1360.00 & 1344.82 & 15.18 & 0.097 \\
\hline 29 & 1318.00 & 1344.82 & -26.82 & 0.097 \\
\hline 30 & 1394.00 & 1344.82 & 49.18 & 0.097 \\
\hline
\end{tabular}

$65 \%(\mathrm{v} / \mathrm{v})$ of acetone, $6 \%$ solid-to solvent ratio for 60 minutes at $60^{\circ} \mathrm{C}$ were suggested using the statistical model equation with optimal total phenolic content of $1394.01 \mathrm{mg} / \mathrm{kg}$. Validation of the regression model was conducted using the conditions above. The experimental value was determined to be $1392.20 \pm 2.9$ $\mathrm{mg} / \mathrm{kg}$ which was in agreement with that predicted by the model.

Higher amounts of phenolic compounds were mobilised around the optimised conditions. The chromatographic methods allowed quantification of individual phenolic compounds present in the extracts without any interference. The HPLC method may not well resolve all phenolic compounds in the extract. For instance, oligomeric flavanols which represent about $71 \%-90 \%$ of polyphenolic content in apples [31], were not observed in extracts under HPLC used because they might not be retained by the stationary phase. 


\section{Conclusion}

The research demonstrated the application of statistical tools to design experiments for optimisation of recovery of polyphenolic compounds from cider apple pomace using aqueous acetone as solvent. Model equations were generated for selected phenolic compounds by studying the influence of acetone concentration, solid-solvent ratio, temperature and extraction time on extraction of polyphenolic compounds. The independent variables have shown selectivity towards efficient recovery of selected polyphenolic compounds. Improving the polarity of acetone by adding water sufficiently improved recovery of Chlorogenic acid and Procyanidin B2. Quercetin-3-glucoside and Quercetin-3-galactoside exhibited different relationship with temperature and solid-to-solvent ratio although both are classified under Quercetin glycosides. The experimental design predicted $65 \%(\mathrm{v} / \mathrm{v})$ acetone, $6 \%(\mathrm{w} / \mathrm{v})$ solid-to-solvent ratio, 60 minutes extraction time at $60^{\circ} \mathrm{C}$ as optimum conditions for extracting polyphenolic compounds from the by-product of apple juice and cider production.

\section{Acknowledgements}

We acknowledge Universal Beverages Limited (UBL), UK for supplying the cider apple pomace residue and Ghana Education Trust Fund (GETFund) for financial support.

\section{Conflicts of Interest}

There are no conflicts of interest as regards this publication.

\section{References}

[1] Neumaier, A. (2004) Mathematical Model Building, Chapter 3. In: Kallrath, J., Ed., Modeling Languages in Mathematical Optimization, Kluwer, Boston, MA. https://doi.org/10.1007/978-1-4613-0215-5_3

[2] Abramowitz, M. and Stegun, I.A. (1968) Chapter 2-Prediction of Medicinal Properties Using Mathematical Models and Computation and Selection of Plant Materials. Computational Phytochemistry, 2018, 43-73. https://doi.org/10.1016/B978-0-12-812364-5.00002-X

[3] Frejd, P. (2013) Modes of Modelling Assessment-A Literature Review. Educational Studies in Mathematics, 84, 413-438. https://www.jstor.org/stable/43589797

[4] Tauber, M.J. and Ackermann, D. (1991) Mental Models and Human Computer Interaction 2. Elsevier Science Publishers B.V., North-Holland.

[5] Çam, M. and Aaby, K. (2010) Optimization of Extraction of Apple Pomace Phenolics with Water by Response Surface Methodology. Journal of Agricultural and Food Chemistry, 58, 9103-9111. https://doi.org/10.1021/jf1015494

[6] Pinelo, M., Ruiz-Rodriguez, A., Sineiro, J., Reglero, G. and Núñez, M.J. (2007) Supercritical Fluid and Solid-Liquid Extraction of Phenolic Antioxidants from Grape Pomace: A Comparative Study. European Food Research and Technology, 226, 199-205. https://doi.org/10.1007/s00217-006-0526-3

[7] Silva, E., Rogez, H. and Larondelle, Y. (2007) Optimization of Extraction of Phenolics from Inga Edulis Leaves Using Response Surface Methodology. Separation and 
Purification Technology, 55, 381-387. https://doi.org/10.1016/j.seppur.2007.01.008

[8] Gilmour, S.G. (2006) Response Surface Designs for Experiments in Bioprocessing. Biometrics, 62, 323-331. https://doi.org/10.1111/j.1541-0420.2005.00444.x

[9] Bezerra, M.A., Santelli, R.E., Oliveira, E.P., Villar, L.S. and Escaleira, L.A. (2008) Response Surface Methodology (RSM) as a Tool for Optimization in Analytical Chemistry. Talanta, 76, 965-977. https://doi.org/10.1016/j.talanta.2008.05.019

[10] Bas, D. and Boyaci, I.H. (2007) Modeling and Optimization I: Usability of Response Surface Methodology. Journal of Food Engineering, 78, 836-845. https://doi.org/10.1016/j.jfoodeng.2005.11.024

[11] Box, G.E. and Draper, N.R. (2007) Response Surfaces, Mixtures and Ridge Analyses. 2nd Edition, John Wiley \& Sons, New York. https://doi.org/10.1002/0470072768

[12] Gunst, R.F. (1996) Response Surface Methodology: Process and Product Optimization Using Designed Experiments. Technometrics, 38, 284-286.

https://doi.org/10.1080/00401706.1996.10484509

[13] Myers, R.H., Montgomery, D.C. and Anderson-Cook, C.M. (2009) Response Surface Methodology: Process and Product Optimization Using Designed Experiments. John Wiley \& Sons, New York.

[14] Shalini, R. and Gupta, D.K. (2010) Utilization of Pomace from Apple Processing Industries: A Review. Journal of Food Science and Technology, 47, 365-371.

https://doi.org/10.1007/s13197-010-0061-x

[15] Cetkovic, G., Canadanović-Brunet, J., Djilas, S., Savatović, S, Mandić, A. and Tumbas, V. (2008) Assessment of Polyphenolic Content and in Vitro Antiradical Characteristics of Apple Pomace. Food Chemistry, 109, 340-347.

https://doi.org/10.1016/j.foodchem.2007.12.046

[16] Guyot, S., Marnet, N., Sanoner, P., et al. (2003) Variability of the Polyphenolic Composition of Cider Apple (Malus Domestica) Fruits and Juices. Journal of Agricultural and Food Chemistry, 51, 6240-6247. https://doi.org/10.1021/jf0301798

[17] Sato, M.F., Vieira, R.G., Zardo, D.M., Falcão, L.D., Nogueira, A. and Wosiack, G. (2010) Apple Pomace from Eleven Cultivars: An Approach to Identify Sources of Bioactive Compounds. Acta Scientiarum Agronomy, 32, 29-35. https://doi.org/10.4025/actasciagron.v32i1.3176

[18] Ibrahim, S., Santos, R. and Bowra, S. (2019) Optimisation of Organic Solvent Mediated Solubilisation of Apple Pomace Polyphenolic Compounds Using Response Surface Methodologies. International Journal of Chemistry, 11, 1-21. https://doi.org/10.5539/ijc.v11n2p1

[19] Schieber, A., Keller, P. and Carle, R. (2001) Determination of Phenolic Acids and Flavonoids of Apple and Pear by High-Performance Liquid Chromatography. Chromatography A, 910, 265-273. https://doi.org/10.1016/S0021-9673(00)01217-6

[20] Joshi, V.K. and Attri, D. (2006) Solid State Fermentation of Apple Pomace for the Production of Value Added Products. Natural Product Radiance, 5, 289-296.

[21] Kennedy, M., List, D., Lu, Y., Newman, R.H., Sims, I.M, Bain, P.J.S., Hamilton, B. and Fenton, G. (1999). Apple Pomace and Products Derived from Apple Pomace: Uses, Composition and Analysis. Springer, Berlin, Heidelberg. https://doi.org/10.1007/978-3-662-03887-1_4

[22] Sun, J., Chu, Y.-F., Wu, X. and Liu, R.H. (2002) Antioxidant and Antiproliferative Activities of Common Fruits. Journal of Agricultural and Food Chemistry, 50, 
7449-7454. https://doi.org/10.1021/jf0207530

[23] Serena, C.M., William, M. and Crozier, A. (2007) Flavonoids and Chlorogenic Acid Profiles of English Cider Apples. Journal of the Science of Food and Agriculture, 87, 719-728. https://doi.org/10.1002/jsfa.2778

[24] Diñeiro, G.Y., Valles, B.S. and Picinelli, L.A. (2009) Phenolic and Antioxidant Composition of by-Products from the Cider Industry: Apple Pomace. Food Chemistry, 117, 731-738. https://doi.org/10.1016/j.foodchem.2009.04.049

[25] Suarez, B., Ángel L. Álvarez, Yolanda Diñeiro García, de Barrio, G. Lobo, A. P., \& Porra, F. (2010) Phenolic Profiles, Antioxidant Activity and in Vitro Antiviral Properties of Apple Pomace. Food Chemistry, 120, 339-342. https://doi.org/10.1016/j.foodchem.2009.09.073

[26] Wijngaard, H.H. and Brunton, N. (2010) The Optimisation of Solid-Liquid Extraction of Antioxidants from Apple Pomace by Response Surface Methodology. Journal of Food Engineering, 96, 134-140. https://doi.org/10.1016/j.jfoodeng.2009.07.010

[27] Tsao, R. and McCallum, J. (2009) Chemistry of Flavonoids. Blackwell Publishing, Ames, IA.

[28] Vasantha Rupasinghe, H.P., Kathirvel, P. and Huber, G.M. (2011) Ultrasonication-Assisted Solvent Extraction of Quercetin Glycosides from 'Idared' Apple Peels. Molecules, 16, 9783. https://doi.org/10.3390/molecules16129783

[29] Pérez-Jiménez, J., Arranz, S. and Saura-Calixto, F. (2009) Proanthocyanidin Content in Foods Is Largely Underestimated in the Literature Data: An Approach to Quantification of the Missing Proanthocyanidins. Food Research International, 42, 1381-1388. https://doi.org/10.1016/j.foodres.2009.07.002

[30] Le Bourvellec, C. and Renard, C. (2012) Interactions between Polyphenols and Macromolecules: Quantification Methods and Mechanisms. Critical Reviews in Food Science and Nutrition, 52, 213-248. https://doi.org/10.1080/10408398.2010.499808

[31] Vrhovsek, U., Rigo, A., Tonon, D. and Mattivi, F. (2004) Quantitation of Polyphenols in Different Apple Varieties. Journal of Agricultural and Food Chemistry, 52, 6532-6538. https://doi.org/10.1021/jf049317z 